\title{
COVID-19-A Sputnik Moment to Revitalize Oscillometry
}

\author{
Neeraj Gupta ${ }^{1}$ (D) Anil Sachdev ${ }^{1} \cdot$ Suresh Gupta ${ }^{1} \cdot$ Dhiren Gupta ${ }^{1}$ \\ Received: 19 November 2020 / Accepted: 16 February 2021 / Published online: 2 March 2021 \\ (C) Dr. K C Chaudhuri Foundation 2021
}

To the Editor: Spirometry, the benchmark investigation for functional appraisal of respiratory system, requires subject's active cooperation and is practically impossible in preschoolers, during sleep, and in those, with neuromuscular weakness, post-cardio-thoraco-abdominal surgery or on ventilatory support. In the current COVID-19 pandemic, its utility has further diminished due to risk of aerosolizing the virus [1]. Apart from these limitations, the ability to reliably detect peripheral obstruction and lung parenchymal diseases needs improvization [2].

Oscillometry, an age-old sound impulse-based technique to determine respiratory impedance, works at normal tidal breath [3]. Being a passive manoeuvre requiring minimal subjective efforts, oscillometry has many advantages over conventional spirometry in terms of operational feasibility (in children, elderly, and those with poor muscular reserves or intellectual deficit) and better sensitivity (in peripheral airway disease and lung fibrosis) [3]. Another potential advantage is lesser aerosol generation as highlighted by Gupta and colleagues, making it suitable during active viral infections [1].

In the current pandemic situation, large number of patients with respiratory problems are managed unmonitored due to imposed restrictions on spirometry. Increasing number of patients with COVID-associated pneumonia and residual pulmonary fibrosis also need to be monitored over time to improve lung age and quality of life. Oscillometry can be safer in these circumstances while taking care of other protective strategies [1]. Though the impulse-based technique seems to have a good potential, population-based age- and height-matched nomograms need to be defined. King et al. have recently provided cutoff values to determine significant bronchodilator reversibility [4].

Physicians have always been on the lookout for an alternative parameter to assess pulmonary functions in difficult situations. Oscillometry can be a value addition to spirometry in adults, whereas it can be a replacement modality in children and elderly. The feasibility with added safety, makes its indepth exploration worthwhile.

\section{Declarations}

Conflict of Interest None.

\section{References}

1. Gupta N, Sachdev A, Gupta D. Oscillometry-A reasonable option to monitor lung functions in the era of COVID-19 pandemic. Pediatr Pulmonol. 2021;56:14-5.

2. Pakhale S, Sumner A, Coyle D, Vandemheen K, Aaron S. (Correcting) misdiagnoses of asthma: a cost effectiveness analysis. BMC Pulm Med. 2011;11:27. https://doi.org/10.1186/1471-246611-27.

3. Starczewska-Dymek L, Bozek A, Dymek T. Application of the forced oscillation technique in diagnosing and monitoring asthma in preschool children. Adv Respir Med. 2019;87(1):26-35.

4. King GG, Bates J, Berger KI, et al. Technical standards for respiratory oscillometry. Eur Respir J. 2020;55(2):1900753. https://doi.org/ 10.1183/13993003.00753-2019.

Publisher's Note Springer Nature remains neutral with regard to jurisdictional claims in published maps and institutional affiliations.

Neeraj Gupta

drneeraj1979@gmail.com

1 Department of Pediatrics, Institute of Child Health, Sir Ganga Ram Hospital, Rajinder Nagar, New Delhi 110060, India 